Research Article

\title{
Wisdom and Curiosity Among Older Learners: Elucidating Themes of Well-Being from Beautiful Questions in Older Adulthood
}

Craig A Talmage ${ }^{1,+, *}$, Richard C Knopf ${ }^{2,+}$

1. Hobart \& William Smith Colleges, 300 Pulteney Street, Geneva, New York, 14456, USA; Talmage@hws.edu

2. Arizona State University, 411 N. Central Ave, Suite 550, Phoenix, AZ 85004, USA; Richard.Knopf@asu.edu

† These authors contributed equally to this work.

* Correspondence: Craig A Talmage, Talmage@hws.edu

Academic Editor: Lisa Hollis-Sawyer

Special Issue: Got Aging? Examining Later-life Development from a Positive Aging Perspective

OBM Geriatrics

2018 , volume 2 , issue 4

doi:10.21926/obm.geriatr.1804025
Received: October 30, 2018

Accepted: December 24, 2018

Published: December 25, 2018

\begin{abstract}
Background: Wisdom and curiosity require greater attention in the lifelong learning literature pertaining to older adulthood. Lifelong learning can assist older adults in amalgamating wisdom and pursuing their curiosities, but how wisdom is amalgamated and how curiosity is pursued in older adulthood needs more exploration.

Methods: This qualitative study investigates subthemes of wisdom amalgamation and curiosity pursuits elucidated from interviews of older adults who participated in a universitybased lifelong learning institute. Specifically, older adults were asked to share their big and beautiful questions with the interviewer in order to develop thick descriptions for analysis.

Results: This study highlights nine subthemes of wisdom amalgamation and nine subthemes of curiosity pursuits that can be linked to lifelong learning. Openness, asking questions, and making wise decisions were deemed top subthemes for wisdom amalgamation. Learning
\end{abstract}

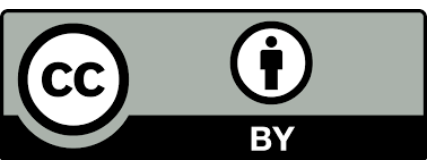

(C) 2018 by the author. This is an open access article distributed under the conditions of the Creative Commons by Attribution License, which permits unrestricted use, distribution, and reproduction in any medium or format, provided the original work is correctly cited. 
about topics, finding purpose and meaning, and asking small and big questions were showcased as top subthemes of curiosity pursuits.

Conclusions: This study provides the groundwork for utilizing big and beautiful questions as a research method to explore wisdom and curiosity. The study also highlights salient themes of wisdom and curiosity present in older adulthood, which may tie to overall well-being and quality of life.

\section{Keywords}

Lifelong learning; third age; gerontological education; quality of life; adult education

\section{Introduction}

Aside from a traditional acknowledgment that the wisdom of older persons must be passed on to younger generations [1], the construct of wisdom has received far less attention in lifelong learning research than the construct of knowledge. Wisdom may be an achieved attribute, but it does not need to be relegated to the later stages of older adult life as an earned reflection at the end of life. At the same time, wisdom may be accrued through breadth and depth of experience and longevity, which has important implications for lifelong learning research and practice.

Wisdom is cultivated by and linked to curiosity [2], but this link has not received a large amount of attention in lifespan development research. Moreover, research on aging populations has often overlooked the role of curiosity in aging [3], despite curiosity demonstrating connections to enhancements in memory, health, wellbeing, and longevity [3, 4, 5]. Unfortunately, curiosity is also known to decline as individuals get older [3], and many adults cease to ask big and beautiful questions as they age [6].

This qualitative study calls for greater consideration of wisdom and curiosity in lifelong learning for older adults. In particular, the study speaks to how wisdom and curiosity may enhance wellbeing for older adults by highlighting salient subthemes of wisdom and curiosity shared by lifelong learners. This study elucidates these connections by exploring the beautiful questions [6] and shared reflective stories $[7,8]$ of older adults engaged in a lifelong learning institute. The subthemes, questions, and literature discussed inform both lifelong learning research and practice.

\subsection{Wisdom in Older Adulthood and Lifelong Learning}

While wisdom has been discussed in philosophical and theological traditions since the time of Ancient Greece [9, 10,11], it gained prominence in psychological research in the 1970s [12]. In the 1980s, wisdom was seen as the primary force that could allow individuals to accept their eventual separation from life and leave a legacy, mark, or positive memory [13]. Since then, wisdom research in psychology has generally fallen into five areas: (1) wisdom defined in practice; (2) psychological measurement of wisdom; (3) wisdom development; (4); wisdom plasticity; and (5) application of the psychology of wisdom $[12,14]$. Furthermore, some psychological researchers have called research on wisdom to be a growing field of inquiry [12], and such research may be gaining traction in positive psychology $[11,15,16]$. 
Positive psychology researchers such as Moraitou and Efklides connect wisdom to hope, and they connect wisdom thinking to hopeful thinking [11]. They speak of wisdom as both a synthetic skill and analytical skill. As a synthetic skill, wisdom allows individuals to deal with uncertainty in life through acknowledgment and interaction. As an analytical skill, wisdom is instrumental, allowing individuals to utilize their accumulated knowledge to deal with dilemmas. Hope or hopeful thinking connected to wisdom or wisdom thinking may provide pathways for thought and promote agency thinking allowing individuals to develop these different facets of wisdom [11]. Moraitou and Efklides have also showcased work connecting wisdom thinking and hope with affect and memory in older adulthood [17].

A few lifelong learning researchers have shifted their attention to wisdom and its importance in older adulthood. Early evidence indicates that lifelong learning can develop and increase wisdom among older adults [18]. Wisdom gained in lifelong learning appears to require voluntary reflection on learning and life $[19,20]$. Lifelong learning keeps older adults active, and reflection is an active choice [7, 20]; both are made available through greater flexibility regarding how older adults can use and view their time each day, generally after retirement [20]. Lifelong learning provides older adults with meaningful activities and purpose in life [20]. Russell writes, "There is also the potential for reflection and wisdom that come from a heightened sense of self and the empowerment of time" [20].

As noted earlier, wisdom occurs in older adulthood where self-development and the preparations for the end of life meet in the minds of older adults [13, 20]. Russell writes, "the seeming paradox of the time factor is explained in existential terms. Life-on-earth time is running out yet later-life learners claim they have all the time in the world and there is no hurry" [20]. Older adults thus display a sense of vibrancy from lifelong learning and the cultivation of wisdom. Lifelong learning provides an active way for older adults to search for wisdom and meaning in life [20]. Lifelong learning also helps older adults satisfy and develop their curiosities through asking and seeking answers to large questions, another component of wisdom [2,12, 21], which will be discussed later in more depth.

Lifelong learning also provides a venue for older adults to share their stories and reflections [7, 8]. Garnet and colleagues write of the importance of storytelling, "Story-telling is a particular medium for expressing 'wisdom' gained from living a life" [7]. Through storytelling, older adults can draw on the past and present to give meaning and understanding to the information they have gained from prior experiences. The significance of autobiographical narratives and storytelling are well researched in gerontology [22, 23], and many lifelong learning programs provide older adults opportunities for writing autobiographical narratives and storytelling [24].

Critical reflection, as part of wisdom, may be expressed in how individuals share not just their stories, but also what they have learned with others $[25,26]$. Farquar argues that older adult lifelong learners need outward expression regarding what they have learned [26]. Lifelong learning can help older adults outwardly express what they have learned and help them build upon the wisdom they already possess [27].

What can be concluded is that wisdom is about seeking answers, asking questions, practicing what is learned, and sharing what is learned with others [27, 28]. Jarvis writes, "wisdom lies in devoting time in seeking to understand our human life and in living it for the common good" [27]. Lifelong learners who seek to live life for the common good do so in community with others; however, the transformative power of community in developing wisdom through lifelong learning 
programs is far under researched [29, 30]. Furthermore, there may be little interest in lifelong learning programs for older adults to cultivate wisdom [31].

Acknowledging the previous work on wisdom and wisdom in lifelong learning, this qualitative study investigates the following question: What lessons can lifelong learning institutes learn about the wisdom of older adults from their lifelong learners? This research identifies subthemes of wisdom amalgamation that relate to lifelong learning research and practice.

\subsection{Curiosity and Beautiful Questioning in Older Adulthood and Lifelong Learning}

Curiosity has been posited to empower older adults with a more positive aging process [7]. As already noted, curiosity is an important quality of wisdom [2, 12]. Lamb, Brady, and Lohman define curiosity as, "Sustained inquiry and wonder as reflected by enthusiasm and interest in opportunities for new learning and experience" [32]. While curiosity requires openness to new experiences [32], it also requires nurturing via learning opportunities and resources and social opportunities and resources [7]. Fittingly, lifelong learning can foster curiosity among older adult learners through its intellectual and social opportunities and resources [18].

Lifelong learning is a method for older adults to satisfy their curiosities and derive self-esteem and pleasure from such satisfaction [21]. Lifelong learners are not just curious about subjects, they are more broadly curious about life [33]. They are curious about their internal resources and capacities [34]. Individuals are also socially curious about their social milieu [35, 36]. Bencivenga writes of social curiosity, "Curiosity is what pushes the participants [older adults] to interact with others, mainly relatives and friends" [35].

Pstross and colleagues write of wisdom as part of a pursuit towards cognitive vibrancy, where through curiosity unknown new knowledge and wisdom are discovered [29]. While much attention has been given to potential cognitive decline in older adulthood [37], perhaps, greater attention should be paid to curiosity decline as individuals age [6]. This is relevant to lifelong learning providers, because intellectual curiosity still remains the primary motive for participation in lifelong learning [38].

The decline in curiosity as humans get older is well-known [3], but not heralded as a high concern in aging and lifelong learning research. More recently, Warren Berger suggested that declines in curiosity are related to declines in asking what he calls beautiful questions [6]. Berger's take on questions appears novel. He explains that individuals who are innovative, creative, and have large-scale impacts on society tend to be expert questioners. They ask ambitious and big questions that can be acted upon [6]. While Berger's work highlights the questions of popular successful entrepreneurs and enterprisers, he suggests that questioning is a skill that can be developed and sustained [6]. Fittingly, the role of questions regarding sustaining curiosity has been consistently acknowledged in education research [39].

Big and beautiful questions are not necessarily grand philosophical questions, such as "why are we here?" Still, beliefs, assumptions, and decisions-made are challenged by big and beautiful questions. Big and beautiful questions epitomize curiosity and innovative outcomes. For example, the innovators of AirBnB asked, "Why should you be stuck without a bed if I've got an extra air mattress?" [6]. But, questioning is not relegated to only for-profit motives; questioning can also be used to better connect with others and charitable aims, such as getting water to those who need it 
most (e.g., Water.org). At the core of big and beautiful questioning are a prioritization of and a dedication to lifelong learning from a holistic rather than reductionist perspective [6].

Lifelong learning likely can provide individuals with opportunities to ask the kinds of beautiful questions that Berger has deemed as important; however, the kinds of questions that are propelling older adults toward lifelong learning are not often researched. Older adults appear to want both breadth and depth in lifelong learning [40]. Specifically, Talmage and colleagues' analysis of enrolment figures in a large lifelong learning program for older adults found that third age learners enrol in a broad array of courses that may cover multiple topics, but they also show interest in dive deep into particular subjects or moments, such as Beethoven's middle period [40].

Older adult learners often take courses outside of their previous careers or fields. They tackle problems they have not addressed before. Considering these notions, this study investigates: What lessons can lifelong learning institutes learn about the curiosity of older adults from their lifelong learners? This research showcases subthemes of curiosity, as a pursuit, that relate to lifelong learning research and practice, and compares them to the elucidated curiosity subthemes.

\section{Materials and Methods}

\subsection{Data Collection}

Researchers from the Osher Lifelong Learning Institute at ASU (OLLI) conducted this study. In order to explore the learning experiences of members in this university lifelong learning program, one of the authors conducted a series of 26 interviews with a total of 26 participants between January and June 2017. The participants included 9 men and 17 women, whose age (50+) entitles them to participate in this lifelong learning program at the university. All but one interview were carried out one-on-one; a married couple participated in one of the interviews together. Due to technical difficulties, recordings from two of the interviews were not preserved. To capture the data, one of those interviews was repeated. The recording time of the interviews ranged from 20 to 78 minutes in length (average 48 minutes long).

In order to select interviewees, the researchers used the criterion that the participants had to be substantially involved in the lifelong learning offerings provided by OLLI. Participants were recruited based on recommendations of the OLLI'S staff and invitations were extended to the OLLI's fundraising committee. Additionally, the lead interviewer visited a number of classes on some of the OLLI's campuses with the intent to meet new people and recruit participants.

Given the exploratory nature of the study, the questions posed by the interviewer were less structured during the first few interviews and had become more focused during peer debriefing among the authors, either in person or via email. Building on Berger's book [6], all interviews included a prompt seeking elucidation of the questions participants are pursuing as they engage in lifelong learning. Further, participants were asked questions about their childhood, their careers, and about lifelong learning activities within and outside of the lifelong learning program. The script, however, was loosely structured, and each interview had slightly different focuses. In an informal manner, the interviews also included some evaluative segments about what the participants liked or felt that should be improved about the OLLI's programs. The participants themselves sometimes brought up such a commentary without being prompted.

Example questions and prompts included: 
1. In the past week/year, has there been a particular question (or issue) that has interested/concerned/fascinated you?

2. How have these questions changed from when you were younger? How are these questions different from the questions you might have had when you were younger? When you were younger, what questions interested/concerned/fascinated you the most?

3. Describe the ways the Osher Lifelong Learning Institute at ASU (OLLI) has helped you address the questions we previously discussed. How has the OLLI helped you generate new/more/better questions? What new questions has the Osher OLLI brought forth in your life? What role does learning play in helping you address the questions you mentioned?

These questions provided rich qualitative data to be analysed and not all of their answers are included in this writing and subsequent analyses.

Prior to conducting this study, the authors submitted their protocols, questions, and recruitment strategies for review by Arizona State University's Institutional Review Board (identification code: STUDY00005585; approved 25 January 2017). In the 1970s, institutional review boards originated in the United States. They comply with the Declaration of Helsinki and are guided by the ethical principles found in the Belmont Report. These boards, which are often located at colleges and universities, aim to protect human subjects from harm, reduce conflicts of interest, and establish public trust in research [41].

\subsection{Data Analysis}

All interviews were transcribed using GoTranscript (https://gotranscript.com), which transcribes the audio via computer listening software not human listeners. The authors then coded the transcript data. In order to get a better sense of the data, the transcripts were first coded in Microsoft Word using open codes and divided into broader groups of data: (1) Personal history, (2) learning activities, and, (3) reflections, using the qualitative data analysis software MAXQDA (version 2018). Drawing from this preliminary analysis and from literature on lifelong learning, the authors then created a template containing the two themes wisdom and curiosity in the second round of analysis. A content coding approach was used to elucidate subthemes within both themes, which was conducted using Microsoft Word and Adobe Acrobat PDF Reader.

Strategies for rigor and trustworthiness were employed. Trustworthiness measures included reflexivity, peer debriefing, member checking, and thick descriptions [42]. Throughout the study, the researchers reflected on findings and discussed them in-person, via phone, and over email.

As already noted, the data analysis began by first identifying themes of wisdom and curiosity present among the lifelong learners' responses. At the highest level, wisdom was seen as advice given to others from the older adults interviewed, and curiosity represented questions shared and/or items raised by the older adults that they wanted to answer or explore through learning more about themselves, others, and the world. A single researcher extracted the relevant responses related to these two overarching themes. A second researcher reviewed the responses coded as wisdom amalgamation and curiosity pursuits before the next round of coding. More specifically, this second researcher looked for how wisdom was amalgamated and how curiosity was pursued by the lifelong learners interviewed, based on their responses. 
This second researcher elucidated frequently observed subthemes for both wisdom amalgamation and curiosity pursuits by going through the responses related to wisdom and curiosity separately. These subthemes were constructed and identified amongst the participant responses after writing the literature review for this manuscript, which influenced the subthemes elucidated. Table 1 contains the subthemes for wisdom amalgamation and curiosity pursuits, which are tiered by their observed prevalence amongst the participant responses. The prevalence of these codes for separation into tiers is noted in the table as well. Within the tiers, the subthemes are presented in order of times mentioned. These codes are presented as dimensions of wisdom and curiosity worthy of further research exploration.

Table 1 Observed Subthemes among Wisdom Amalgamation and Curiosity Pursuit Responses.

\begin{tabular}{|l|l|}
\hline Wisdom Amalgamation Subthemes & Curiosity Pursuits Subthemes \\
\hline Top Tier (12 to 20 mentions) & Top Tier (12 to 20 mentions) \\
\hline Being Open to New Pathways & Learning More About Topics \\
\hline Asking Questions and Learning & Finding Purpose and Meaning \\
\hline Making Wise Decisions & Answering Small and Big Questions \\
\hline Middle Tier (6 to 11 mentions) & Middle Tier (6 to 11 mentions) \\
\hline Finding Joy in Life & Seeking Acceptance and Achievement \\
\hline Caring by Giving Back & Worrying About the Future \\
\hline Using Time Wisely & Searching for Good \\
\hline Bottom Tier (5 or less mentions) & Bottom Tier (5 or less mentions) \\
\hline Accepting One's Self & Looking to be More Open \\
\hline Building Community & Listening to Others' Perspectives \\
\hline Looking to the Future & Solving Problems \\
\hline
\end{tabular}

\section{Results}

\subsection{Expressed Wisdom of Older Adult Learners}

The construct of wisdom and its subthemes were present amongst the responses of the lifelong learners interviews. Nine subthemes of wisdom amalgamation were elucidated and separated based on their prevalence (Table 1). The responses reflecting the subthemes are in the forms of both questions and thoughts. Participants and their respective interview numbers are cited as P\#.

3.1.1 Being open to new pathways. Encouragement to others to be more open was advice shared by the older adult learners sometimes (but not always) directed towards younger persons. "Keep your mind open," (P9) was said. Another participant commented that openness is about not limiting oneself:

"You don't have to limit yourself to anything in particular that-- When you're in school you don't have to follow a certain path of life. The whole world is open to you. You can choose. If you're a woman you can choose science and do whatever you want...But just don't limit yourself, and don't sit back and wait for something to happen to you. It's not going to happen to you. You have to go out there and do it." (P3) 
To the younger generation, one person stated, "I think I would ask young people to be more open to some ideas. Not that they have to dismiss their own, but just listen carefully and see parts of it can fit into your life" (P2).

Openness was connected to action as seen amongst participant responses, showcased by taking risks and conquering fears and limits. One participant noted, "Most of us are smart enough to know when the risk is possible to take, not probable, but possible. The reward is so much better when you take that risk" (P11). Another person highlights:

"Don't dwell on not doing things because you may be afraid to do it or anxious to do it.

That's going to stop you from being the person you can be and we can never stop doing that as far as I'm concerned." (P4)

Still, the decision to address or overcome such risks or fears is an active choice by older adults. One commented, "Take some risks, take some risks, if you want" (P11).

Overcoming fear requires embracing discomfort. "I really think from my leaving my little town and all its comforts that it had to offer, I eschewed those and decided I wanted to figure out who I was and do it on my own first" (P5). Another said, "Do something you haven't done before...outside of your comfort zone" (P11). Embracing discomfort requires departure. "At least, if they go away and then come back, at least they've experienced something else. To just stay is not good" (P7).

The notion of departure from "normal" life activities was showcased in comments encouraging individuals to travel, especially abroad. One noted, "Make sure you take foreign trips before you get too old to go" (P15). Other comments encouraged individuals to explore new areas of study or read books outside their fields. One participant commented, "You can get a lot from fiction. I've sometimes seen a fiction book work describe something that was happening" (P15). Another noted that individuals should take lifelong learning classes outside of their typical areas to expand their mind-sets (P16).

Multiple participants commented that openness required broadening perspectives. One said, "Broaden up your perspective when you have the opportunity to do that through whatever means possible" (P4). Referring back to travel, one participant stated, "Find something outside your field to think about. Travel. Travel, certainly, is broadening" (P15). Another suggested, "Learn an instrument, learn a foreign language, take a class, learn how to knit. Do something that is new and challenging" (P19). One participant noted that prior knowledge and identities should not limit individuals from expanding their fixed mind-sets stating:

"You mathematicians, take an art class. You should be taking classes in other areas than

what you think your fixed mind-set is in. You're not just a swimmer. You're not just a dancer.

You're not just an artist. Don't have a fixed mind-set about things." (P16)

Finally, openness was linked to well-being. Individuals who are open may have already been open- (and not fixed-) minded. One learner commented, "I think that the people who flourish are really the ones who had a life to begin with" (P20). Openness may come from a change in direction for individuals who are not already open (P23).

3.1.2 Asking questions and learning. Older adults in this study recognized the importance of asking questions and continuing to learn. One learner encouraged, "Go out and find answers. Find people who you trust to give you advice" (P3). Another said, "never stop learning" (P4). "Just learn and pay attention" (P12), another commented. One learner stated, "Keep learning, absolutely" 
(P19). Importantly, participants encouraged individuals to learn new things and learn about new topics, but individuals need to identify those topics early on.

Asking questions and learning allows individuals to recognize their full potential. Some participants commented on the introspection provided by asking questions and learning, while others noted that questions and learning helped them better understand others. One participant commented, "You can't tell people what to do. You have to ask questions, and get them thinking for themselves about what their potential is" (P3). Another noted:

"You have to keep learning to know yourself better and to be honest with yourself to know who you really are, and of course one way to do that is to reach out into places that you otherwise might not go... you have to build your foundation for now and keep doing it. You never stop learning" (P21).

This learning, especially to understand self and others, required a great deal of listening (P22).

Learning was also not just for finding answers but for fun as well. "When you're in school, you study for the test and study for the grade. When you get to the point where you can do this learning just for the fun of it, you'll learn a lot more" (P13). One participant encouraged individuals to start with simple tasks first (P16). Another encouraged individuals to try out one class first to see if they liked it (P20).

3.1.3 Making wise decisions. Participants noted the importance of making wise decisions throughout one's life trajectory. One participant specifically focused on spending money wisely, but also enjoying how they spent their money. "I would challenge people to make sure that they're contributing and earning their way along with enjoying what they're doing" (P5). One participant noted that individuals should not work for superficial gains; "They want to get out and get a job so they can buy a car, so they can run around" (P9).

Personal awareness and responsibility for decision-making was emphasized. One participant stated, "If I had a podium and talking to young kids, it would be, don't follow your friends, find out who you are first" (P7). One participated stated, "You need to think before you speak" (P22). Again, while most of the responses did not concern the younger generation, another criticized the younger generation by saying,

"I guess the third piece of advice I'd say is literally stop whining. You start to complain about something; I don't even want to hear it. It's nobody's fault but your own. Even if it is somebody else's fault, it's your own problem. You have to learn to cope with it. You either go through it, around it, over it or figure out a way but don't whine. Work the problem."

The same participant furthered this comment by noting that a "why me, mentality" was unproductive, and that perseverance was needed (P16).

Another participant noted that individuals should not give up on curiosity. This person stated, "I've just seen people shut a door, and they don't know what's on that other side" (P20). In the same light, one participant believed that every person should: "follow your dream" (P19). Good choices and pursuits were linked to bringing individuals joy. One participant spoke in the following manner about this: "I say to kids, "Be ruthlessly vigilant in how you spend your time"” (P23).

3.1.4 Finding joy in life. Participants encouraged individuals to find joy in life. One participant said, "Find enjoyment where you can" (P4). More specifically, another advised, "enjoy what you're doing when you're doing it" (P5). Multiple participants noted that joy was an everyday pursuit. One participant noted that life was short and that joy was worth pursuing stating, "You ought to 
be doing something for a living that brings you joy and that brings you purpose. If you're not, then you need to find something else" (P23).

One participant linked moments of joy to longer-term happiness by saying:

"You want to be happy. Because if you find something you love, you will joyfully do that, and you will do it well. If you go into something you don't like, you're going to hate it, and you're not going to do it well. So do the exploration now." (P11)

Somewhat contrarily, another participant emphasized that joy and happiness were both active choices made by individuals. This person stated, "It's about you and your attitude" (P16).

3.1.5 Caring by giving back. Some individuals found joy and wisdom in giving back and caring for others. One individual specifically shared that they worked with homeless persons. Others shared that they worked with older adults and individuals with mental health and ability challenges.

Others were more general in their statements. One exclaimed, "Care for your fellow men in all no matter who they are, what their situation is. Do what you can" (P4). Another stated similarly, "You've got to care for and help take care of your fellowmen" (P9). Care for others may be seen as a difficult obligation, because individuals "do not want to let those people down" (P9).

3.1.6 Using time wisely. Time was deemed finite; thus, individuals should seek to maximize the use of their time more meaningfully as they age. Another interviewee noted that individuals, especially of their same age, were wasting their time not going out and doing stuff (P3). Another encouraged individuals to expend more energy (P12). Another participant felt individuals were not following their dreams (P19). Regarding retirement, one participated stated:

"Be thinking about things or what interests you ahead of time, even if you can't indulge in them to the fullest extent. Whether it's a hobby or whether it's you know whatever and start laying the foundation for that, so that you're not just stuck the Monday after the Friday that you retire with not knowing what to do." (P20)

One participant noted that younger persons needed to find more free time to "try and discover...because I think that stops a lot of people from doing things they're interested in" (P1). Finally, one individual stated regrets: "I wish someone had told me is be ruthlessly vigilant in how you spend your time, ruthlessly vigilant...The time I had is short, and it doesn't shine as well as the time behind" (P23).

3.1.7 Accepting one's self. Acceptance of how things are, how they will be, and who one is were noted as important. One participant stated, "Accept the good with the bad, never stop learning, whatever your definition of learning is" (P4). One individual noted the importance of letting others make mistakes and learn from them (P14). Another advised, "I guess my biggest advice is to always be yourself" (P10). Acceptance was linked to happiness, "If you decide to be happy, then everything else just falls into place. You drag a happy cloud around with you, instead of these people who drag black clouds around with them" (P16).

3.1.8 Building community. One individual noted the importance of finding individuals you trust. Another noted the importance of not struggling alone. One individual noted the importance of working with others to address problems. Finally, one person noted the importance of working with individuals you do not necessarily agree with.

3.1.9 Looking to the future. A few individuals noted their care for the future and planning for the future. One individual encouraged younger persons to invest wisely. One individual encouraged others to plan what they want to learn from lifelong learning.

Finally, one participant's comments on wisdom and knowledge are notable. 
"Your knowledge is going to increase in your job, whatever that happens to be, but that may have no bearing at all on the wisdom you develop but it's lasting. Wisdom is transformative in nature and relates to the quality and nature of your life, the meaning of your life and your relationships in life. Whereas knowledge can be more specific and substantive; that's not more, so pay attention to developing the wisdom in your life" (P24).

This person wanted to ensure the interviewer could differentiate knowledge and wisdom.

\subsection{Expressed Curiosity of Older Adult Learners}

The construct of curiosity and its subthemes were expressed amongst the responses of lifelong learners interviews and captured for analysis. Nine subthemes of curiosity pursuits were identified and organized based on their prevalence (Table 1). The responses reflecting the subthemes come in the forms of both questions and thoughts.

3.2.1 Learning more about topics. During one interviewee, a participant asked, "do I have particular areas that I would like to pursue?" (P1). Many participants had answers to this question. Most individuals wanted to further explore specific areas they were interested in, while others wanted to explore new and different topics.

Breadth was evident amongst participant responses. One participant noted they were, "curious about everything and anything...science, history, physics, medicine" (P4). Others noted how particular classes broadened their perspectives. Another participant noted that they were surprised how much they liked different classes. "I was doing a genetics course. I've never ever in my life done that. I took a class in quantum physics one time" (P7). This individual also tended to like classes that concerned politics, sociology, and history.

Some individuals had particular and more singular avenues they wanted to pursue more indepth. One participant noted the following:

"Sciences, that's always number one. Drives my wife crazy, because she wants to watch other things on TV, and I've got the Science Channel on, and I've got National Geographic on, and the Discovery Channel on, and I like that." (P6)

One participant was interested in technology and world affairs (P15). History was mentioned to be particularly interesting for a learner (P7). Another person was interested in Spanish literature from the early 1600 s on (P24). For one learner, they were particularly fascinated by the weather and other earth sciences (P9). Two participants noted the history of science as important (P8, P23). Another individual expressed particular interest in cosmology and astronomy; they stated, "The first time all these little subatomic particles swirled and formed an atomic particle. Consciousness was there at the beginning. I'm just very curious about -- I don't know how to articulate that into a class" (P8). This individual had many questions about life and humanity's place in the universe. Similarly, one individual was interested in psychology, specifically how the mind works (P15). Finally, one individual noted, "I want to preserve my brain the best I can. I'm also curious about what makes us behave the way we do. I'm a person who believes it's nurture and nature" (P23).

3.2.2 Finding purpose and meaning. Some individuals offered big questions and reflections regarding finding purpose and meaning in life. Some were concerned about their individual purpose. Another questioned how they could best help people and care for others. Another wanted to help others live better lives (P23). One wondered about their "destiny" (P4). One questioned if they had choice in their lives given their inherited traits and genes (P9). Another 
questioned humanity's place in the universe (P8). Similarly, one person asked, "Why are we here?" (P11).

One asked questions about what he or she would do if they could do it again, and this person suggested that they might do it differently (P6). One participant wondered the meaning of current events in the world (P7). One person noted interest in "the meaning of life" and philosophical questions (P24). Another person noted that they wanted to keep growing, live fully, and not become stagnant (P20).

3.2.3 Answering small and big questions. Participants noted the link between asking questions and finding answers. One participant wrestled with the differences between asking questions and finding answers in feelings or facts (P3). Another participant noted the importance of asking questions to keep their mind active (P4). Another noted the value of questions compared to answers. "Before I took this class, I didn't even know what some of those questions were. It turns out the questions are more interesting than the answers" (P24).

One person noted the importance of asking questions to evaluate decisions made by others (P3). Another noted the importance of asking questions to understand their own choices (P11). One participant linked questions to their own personal growth (P20). Another noted it was important to ask questions to understand different points of view. One person asked questions regarding how to help others (P3). Another person asked how to give back to others (P4).

Philosophical and big questions were noted as important to two participants (P4, P19). One person commented on pursuing unanswerable questions.

"This is what I'm supposed to be doing. I think there're a lot of unanswerable questions out there. We have to be curious about what those might be, always searching, as long as we have...Some are unanswerable, of course, but one has to be curious and just keep moving forward...Unanswerable questions...seem to have worked out well with me." (P4).

This participant also noted that they had to realize that there is much in life they could not control. Similarly, another participant noted that deep questions take a person back to childhood and through the difficult times in their life. This person stated:

"Because some of the deep questions are related to things that...those were deep questions back in your childhood. They relate to how your grandmother died or you just. You find out that they're very personal and specific. To some extent, you push them away during your working life because they weren't that relevant." (P24)

Finally, one person connected what they were learning in class to understanding their own life.

3.2.4 Seeking acceptance and achievement. Acceptance and achievement from curiosity in life were of note to some participants. These comments in particular concerned reflections back on one's life as the end of life was nigh (P2, P3, P4, P11). One participant states, "I think as you get older, as you age, you have a tendency to look back, not that there's anything wrong with that that's a project to this moment right now so that's okay" (Participant 4). Another individual notes:

"So that you can grow as an individual is not just I've done this, that's the end of that; but, weave it into a tapestry, so when you're laying on your gurney in the hospital, you can say this is what I've done." (P2)

For two individuals, death and dying were major concerns (P11, P24). One individual was concerned about their legacy, so they could be immortal despite being mortal (P20).

One participant questioned their own priorities and balance in life in regards to achievement (P3). The same participant questioned if they took their knowledge with them after they died (P3). 
Similarly, another participant noted they wanted to know everything if they could and linked their thirst for knowledge to their identity (P9).

One participant noted the importance of failure as connected to acceptance. This participant stated, "when you're young, the world is there ahead of you to take and go and do what you want you've got no commitment, so you fall down, you make a mistake, you got time to recover" (P4). Another stated, "I tried that many times over. I can't. It took me a long time to figure that out" (P7). This person noted they still wanted to know who they were and who they could be.

3.2.5 Worrying about the future. Some participants were concerned about the future of the world, its knowledge, and its people. Two individuals were concerned about the future of science and the world (P6, P8), and one individual was particularly interested in the future of technology (P8).

Two individuals were concerned about the futures of their friends and families (P3, P7). An individual wanted young people to prepare for the future, stating concerns about social changes.

"Do you know, since 1960, I read in the paper the other day, how many fewer people are married, buying houses, and it's because they can't afford it? No. This is America, and I think we aren't taking care of the many. The few are doing well. I live very comfortably. I don't have a mortgage. I don't even have a car payment." (P19)

Finally, another person commented, "One question would be, we don't know what the next moment's going to bring. We don't know what the next year's are going to bring" (P4).

3.2.6 Searching for good. Some individuals were concerned about U.S. and world politics. They discussed how they searched for good in the world and the U.S. One person stated, "But generally speaking I'm not a very depressed kind of person. I try to look for the better, even within the political scene" (P2). Two participants wanted to enjoy the news and deal with difficult topics (P3, P10). Another participant wished the U.S. political environment would not be so divisive (P6).

One learner noted good comes from trying to learn "what life is" (P8). Another searched for good in death and medical innovations that prolonged life (P11). Finally, one participant remarked that good often results from luck (P9).

3.2.7 Looking to be more open. One participant critiqued others for not being more open and interested in life. This person stated:

"There's all kinds of different people, but how can people be so insular that all they think about is their job, their coming home and watching TV, they don't think beyond today and maybe next week. They don't question; they don't have any interest in bigger things, understanding how the world works, something that is so critical to your life. They don't have it. How can people not be interested in that? But most people that I've met, it's like, 'Why do you want to know that?'” (P1)

Similarly, one participant exclaimed, "I'm curious about everything" (P4). Another person question if science and facts were the only paths to seeking truth (P3). Finally, a participant thought individuals needed to be more aware and open to change (P11).

3.2.8 Listening to perspectives of others. Though not prevalent, a few participants noted the importance of listening to the perspectives of others. One participant stated:

"Hearing everybody's point of view can be very, in one way consoling, if it's similar to your questions and concerns. Or if it's totally different, it could be confusing, because it brings up more questions that you don't know the answers to." (P3). 
Another commented, "You help people by whoever you run into; you get curious as to what they do and how they do it" (P12). Finally, one participant questioned, "How can I be a better listener, and a better understander, less judgmental?" (P23).

3.2.9 Solving problems. Lastly, a few individuals commented on the importance of problemsolving regarding satisfying their curiosities. One individual addresses learning like a puzzle stating:

"I try to figure out how did they get into this? What's the problem here? It's like a puzzle.

But that's what I did for my living. That was my career. For me to find the piece of the puzzle, that can maybe help them, but gives me an insight into what's going on in the world, not just for them. If they're experiencing it somebody else is too." (P2)

Another participant noted that they felt they were solving problems when relaxing or dreaming. She states, "Sometimes when I dream, it come up with stuff, then I'll tell my husband later" (P16).

\subsection{List of Big and Beautiful Questions}

Table 2 provides a selection of fifty big and beautiful questions elicited from the study participants. While axial codes between wisdom and curiosity could be constructed given the small sample size, the researchers thought to provide readers with a list of questions shared by the older adults for future reference and investigation. While not all these questions may be considered beautiful by Berger's [6] standards, they are certainly big. This table is meant to provide further justification of the subthemes elucidated earlier amongst the participant responses. These questions are also meant to guide future research on big and beautiful questions of older adult lifelong learners. These questions have already been coded regarding wisdom and curiosity subthemes; most of these questions were derived from the curiosity responses.

Table 2 List of Fifty Big and Beautiful Questions of Older Adult Learners

\begin{tabular}{|l|}
\hline 1. Am I solving anybody else's problem by myself learning new things? \\
\hline 2. Can I help people? \\
\hline 3. Do I want to do that? \\
\hline 4. Do I want to do this? \\
\hline 5. Do I want to just continue my life this way? \\
\hline 6. Do we have a purpose? \\
\hline 7. Have I accomplished enough so that I can sit back and relax, or do I need to continue for the rest of my \\
life? \\
\hline 8. How about the next generation? \\
\hline 9. How can I afford what I want to do? \\
\hline 10. How can I be a better listener, and a better understander less judgmental? \\
\hline 11. How can I develop my own unique character well enough that would encompass, who knows, who I \\
\hline 12. How can people not be interested in that? \\
\hline 13. How can they [organizations and others] help me discover? \\
\hline 14. How can they [organizations and others further something that I'm interested in? \\
\hline 15. How did we get here today? \\
\hline 16. How do people come to terms with dying? \\
\hline 17. How do you find commonality? \\
\hline
\end{tabular}




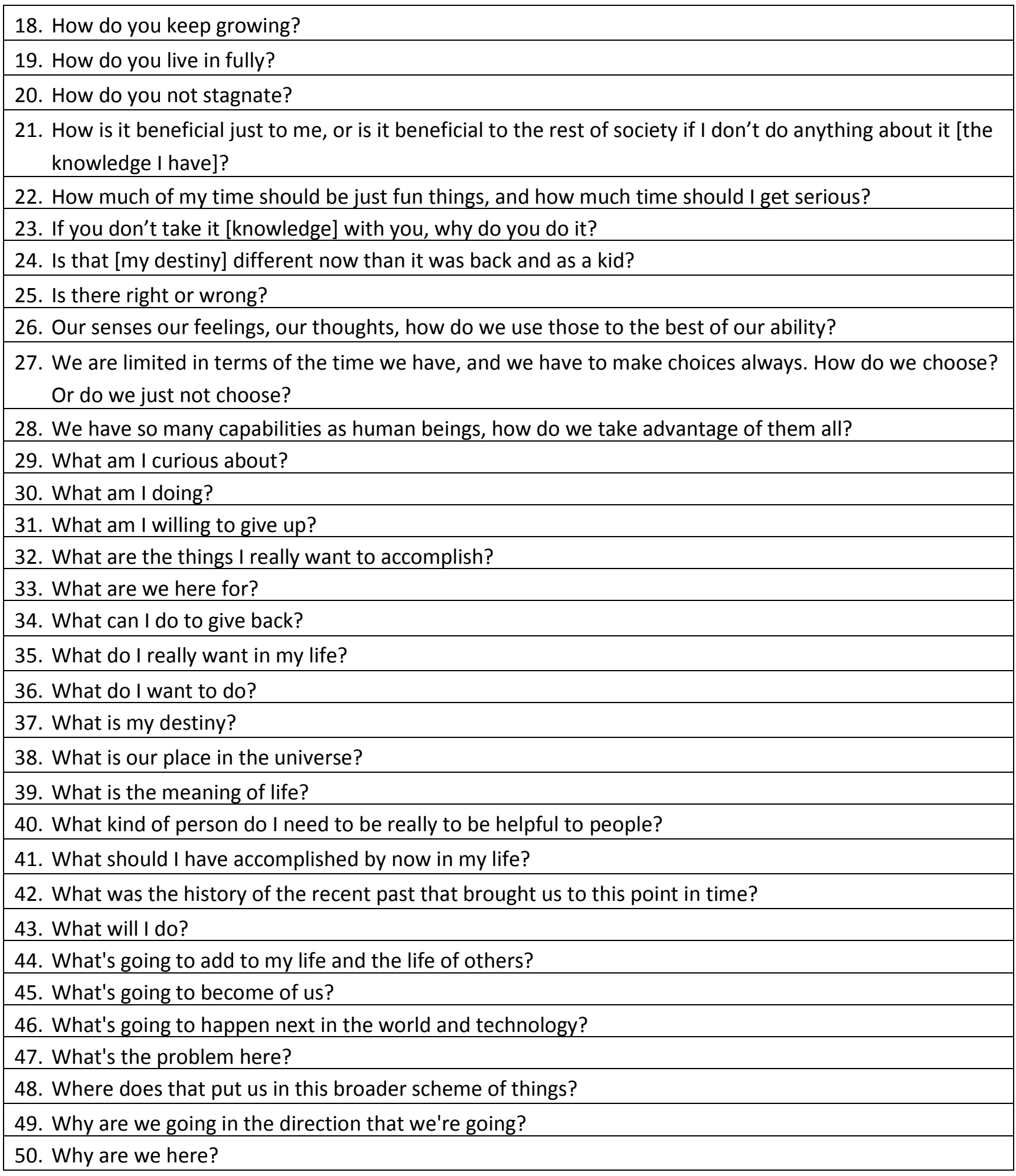

\section{Discussion}

\subsection{Lessons in Wisdom for Older Adults and Lifelong Learning}

The older adults in this study amalgamated wisdom during their lives, and unique subthemes of wisdom amalgamation were identified in this research. Our finding that being positively disposed to openness to new pathways in life appears to be an avenue to wisdom for older adults, which is consistent with past research [32]. New experiences from openness can come from the 
intellectual and social stimulation that comes from lifelong learning programs [7, 18]. These findings suggest that lifelong learning providers need not only be places for older adults to experience new things [21], but also providers can and should work to foster openness among their learners. This will require helping them overcome discomfort regarding trying new things.

Asking questions and learning appeared as another frequently observed wisdom theme. Lifelong learning programs can help older adults answer their questions $[2,12,21]$. This study affirms that while wisdom can come from seeking answers [27, 28], it also comes from asking large questions $[2,6,12,21]$. These questions can range from introspection to global inquiry. Recognizing that questioning may decrease with age [6], lifelong learning programs may assist older adults with developing and reforming their large questions. Congruently, this will require helping older adults overcome fears of asking questions and encouraging them to ask questions. Furthermore, these questions and answers gained from lifelong learning can and should be shared with others $[27,28]$.

Decision-making, specifically wise decision-making, was a particularly important top wisdom theme. Study participants particularly emphasized personal awareness and responsibility for decision-making. These findings may inform new research on the importance of personal awareness of aging to older adult well-being [43]. These findings are also related to the importance of personal awareness to generativity in older adulthood [44]. Noting generativity, older adults in this study wanted the younger generation to be successful like them and to persevere, not complain, or ask "why me?" questions. Perseverance should be investigated in future research, because it may be linked to keeping older adults asking questions, keeping them curious and keeping them open to new experiences. These notions are often found in development education research regarding critical thinking [45]. Finally, the notion of vigilance regarding decision-making may be of interested to future research; one participant advised to be "ruthlessly vigilant," which may be an interesting research concept and practice to investigate. Lifelong learning programs can help older adults make generative decisions and build awareness through their programs and pedagogies, but best practices need to be established and shared.

Wisdom appeared linked to finding joy in life whenever individuals can, if not everyday. The connection between searching for joy and meaning near the end of life is well-researched [46]. As noted in this study, joy is not just an emotion experienced, but also an on-going ideal or pursued goal. The notion that individuals should abandon activities or relationships that do not bring them joy connects with Lars Tornstam's theory of gerotranscendence [47], which has been linked to quality of life measures for older adults $[47,48]$. For some participants, joy is also connected to decision-making and is a personal orientation, whereas it is an active choice and constant attitude. These comments connect with previous definitions of wisdom as pro-social attitudes and behaviors as well as a form of social decision-making [49], which should be explored more in the future. Lifelong learning programs may be places for individuals to experience joy, but also joyful individuals may take part in lifelong learning programs. These impressions require more research.

Caring for others and giving back connect with prosocial behaviors being included in wisdom. Volunteerism in older adulthood is well-researched and has been connected to wisdom [50], meaning in life [51], and well-being [52]. Lifelong learning programs can promote transformative experiences by engaging individuals in their communities [29]. These notions also question whether lifelong learning programs promote altruism in older adulthood [15]. Furthermore, the 
notion of care as an obligation or point of stress, despite its connection to wisdom, should be investigated further.

The participants emphasized the importance of using time wisely, because time was short. Time should be used for seeking joy and searching for good according to the older adults, which is consistent with previous research $[27,28]$. Older adults may be enjoying greater sense of time or flexibility regarding time, but they want others to best use time across their lifespans [20]. Others may have regrets when nearing the end of life [13]. Lifelong learning can provide older adults with a generative way to use their time wisely, but more research is needed in this regard [53].

Study participants linked accepting one's self to wisdom. This link is consistent with Erikson's theory [13]. Erikson's final two stages of psychosocial development (in order) discuss whether older adults (40-65) are generative or stagnant in decision-making and use of time, and discuss whether older adults (65+) look back on their life with ego integrity or despair [13]. Lifelong learning was noted as a vehicle for seeking acceptance and achievement. Acceptance and achievement were also connected to satisfaction and joy in life, which have been substantially researched in the past [54]. Lifelong learning can help individuals correct their past mistakes and/or reframe their thinking, but these claims need further investigation. While well-outside the scope of this study, researchers are exploring autobiographic memory, fluid intelligence, and crystalized intelligence [55], which may inform lifelong learning practice in these regards.

While not a frequently mentioned subtheme among wisdom responses, community-building was identified as important. Older adults desire to work with others they trust to address problems, personal and non-personal. The notion of social stimulation has already been noted, but the strong emphasis on trust in problem-solving would benefit from greater research regarding lifelong learning. These notions may be especially important when working with vulnerable older adults [56]. One individual wanted to dialogue with individuals who did not share their same opinions on larger issues. Learning providers may provide older adults appropriate spaces for debates and dialogues [57].

Future-orientation was not as prevalent among the wisdom responses than among the curiosity responses. These individuals cared about the future and planning for the future. Lifelong learning providers can possibly help individuals plan for their futures including future learning opportunities and care for others in their communities as well. The importance of futureorientations among older adult learners should be examined in future research.

Despite claims of low interest in cultivating wisdom in lifelong learning programs [31], lifelong learning providers can promote wisdom [18]. This research provides nine areas to consider. Openness to new pathways and asking questions to learn have been subjects of past research [27, 28]. Lifelong learning can provide a venue for questions that allow learners to develop their curiosities [2, 12, 21] and to search for wisdom and meaning in life [20]. Lifelong learning can help them continue to utilize and build upon their previous accumulated knowledge $[11,27]$.

Lifelong learning providers can also nurture wisdom by helping learners use their time wisely and make wise decisions. Older adults continue to face uncertainty and dilemmas, which impact how they use their time $[11,20]$. A desire to accept one's self and look to the future relates to previous work regarding leaving a legacy, mark, or positive memory [13] and the importance of hope and hopeful thinking [11]. Voluntary and critical reflection on learning and life are essential to addressing these areas, and they can be facilitated in lifelong learning programs $[19,20,25,26]$. 
Finally, wisdom in older adulthood comes from finding joy in life, which relates to previous work regarding meaningful activities and purpose in life [20]. These meaningful and purposeful activities not only give older adults agency [11] and keep them active [7], but may also allow them to care for others and seek the common good in community with others $[27,29,30]$. While not directly assessed in this study, sharing stories and reflections may help build community and promulgate care and joy $[7,8,22,23,24]$.

\subsection{Lessons in Curiosity for Older Adults and Lifelong Learning}

The older adults in this study pursued their curiosities, and unique subthemes of curiosity pursuits were elucidated in this research. The top subtheme in curiosity was a desire to learn more about topics of interest to study participants. These topics could be new or old interests to learners. This finding is very consistent with previous research showing that older adults desire both breadth and depth in the lifelong learning [40]. It appears from the responses that it may be important for lifelong learning programs to encourage older adults to take classes that they might not have considered before. The success of this potential strategy warrants further investigation. Notably in this study, sciences received a great deal of attention among curiosity responses.

Curiosity helped individuals find purpose and meaning in this study through asking questions (discussed next). Purpose was both introspective and outward facing in that individuals asked how they might help others. Notions of destiny and places in the universe were raised. These notions connect with Tornstam's concept of cosmic gerotranscendence - connection to past and future generations, the universe, and powers behind their control [47]. Cosmic gerotranscendence has been linked to life satisfaction and well-being $[47,48]$. Lifelong learners may be more concerned with larger "why" questions, and lifelong learning programs may be equipped to help them ask these large and more philosophical questions in addition to Berger-style beautiful questions [6].

Curiosity is satisfied and spurred through asking questions, small and large. Answers to questions came in the forms of more questions, finding facts, and experiencing feelings that have not been known before by older adult learners. Again, questions may be introspective or investigative of the world and the universe. Lifelong learning providers can encourage older adults to keep asking questions until they find answers [58] knowing that asking questions may decline over time [6]. The older adult learners also linked asking questions to an active mind; an active mind has been linked to higher health and well-being [59]. Questioning others' decisions was noted by participants and should be investigated further. Questions may also be more important than answers for some older adults, which may relate to questioning's link to spirituality [60]. Lifelong learning providers would do well not to ignore spirituality and questioning in their work.

Older adults sought acceptance and achievement from their curiosity. Again, this fits Erikson's theory, where individuals reflect back on their lives because they are approaching the end of their lives [13]. Leaving a legacy remains important to older adults [61]. Returning to an earlier point, lifelong learning may be an avenue for seeking acceptance and achievement. This acceptance and achievement may require overcoming previous failures, which should be investigated in the future. Similarly, individuals held concerns regarding death and dying, which is common in research [62].

Older adults in this study did have concerns about the future. These notions may relate to leaving a legacy and cosmic gerotranscendence already mentioned. Interestingly, some older adults were worried about the future of technology and scientific inquiry, which should be 
explored in future research. Others were worried about the preparation of future generations and social changes in coming in the future. While outside the scope of this study, intergenerational research and practice in lifelong learning programs may help older adults in this regard $[63,64]$.

Fitting with concerns for the future and also for the present, older adults sought out the good in life or the good in hard times. The current political climate of the United States may be affecting older adults as well as all persons in the U.S.; however, this claim should be further investigated in the context of curiosity (and wisdom). While lifelong learning can provide a forum for discussing current political strife, it also may be a place for individuals to search for good in hard moments.

A smaller theme in curiosity, but larger theme in wisdom was older adults looking to be more open. Curiosity may help individuals in their journeys to be more open. This openness may be connected to individuals finding truth in many ways, not just hard science and facts. Curiosity may help individuals be more open to change and aware of their actions and place in this world. These notions are consistent with Tornstam's gerotranscendence mentioned in greater detail earlier [47], and should be explored further.

Openness connects to another smaller theme regarding listening to the perspectives of others. Participants linked listening to greater empathy and less judgment, which is consistent with prior research $[14,65]$. Research has emerged regarding how to activate curiosity and wisdom in older adulthood and may inform future research in this area $[65,66]$. Lifelong learning may be a tool for learning how to activate listening or improve listening skills $[25,26]$.

Finally, some older adults satisfied their curiosity through solving problems. Lifelong learning programs can present older adults with puzzles and problems to be solved, which can help them better understand the world. This problem solving also can take place in environment without tests or grades taking some of the pressure off older adults as well. More research is needed regarding the best problems and best puzzles for older adults engaged in lifelong learning.

Overall, lifelong learning providers can promote curiosity by addressing these nine areas. Older adults fuel their curiosities to find purpose and meaning, which relates to previous research on older adults' curiosities about life [33]. Older adults continue to desire to learn more about topics new and old, which is congruent with previous research [29, 32, 40]. Lifelong learning providers should continue to provide their learners with both broad and in-depth learning experiences.

While the importance of asking questions in older adulthood has been somewhat discussed and explored [6, 39], this research highlights the importance of asking questions, big and small, to curiosity in older adulthood. As already noted, questions can be promoted by lifelong learning providers. Openness to new experiences and listening to others' experiences, as part of curiosity, are both consistent with previous research as well [18, 32, 35]. While older adults may approach lifelong learning with varying levels of openness, lifelong learning providers can offer intellectual and social opportunities to satisfy their curiosities [18, 21]. In this study, older adult learners seek acceptance and achievement; desire to solve problems; search for good; and, worry about the future. To address these aims, lifelong learning providers can offer resources to address these desires and build the self-esteems, internal resources, and capacities of their learners [21, 34].

\subsection{Questions for Older Adults and Lifelong Learning}

The questions shared by study participants (see Table 2) provide rich information for further research on wisdom and curiosity. Furthermore, asking questions appears linked to the 
development of wisdom and curiosity, but more research is needed to establish a causal or at least stronger link. Still, these questions provide substantial avenues for lifelong learning regarding research and course topics. Perhaps, courses could be organized around these questions. Also, courses can help older adults continue to ask new questions recognizing that they are apt to naturally decrease in the breadth and number of questions that drive them as they age [6].

The tactic of elucidating big and beautiful questions requires further examination and refinement in future studies on older adults. The author who conducted the interviews for this study noted difficulty in getting older adults to respond in the forms of questions. A requirement of individuals to form of a question is commonly only seen in game shows such as Jeopardy! At times, the interviewer had to be patient with the older adult learners and ask them about large concerns or thoughts occupying them in order to generate a question or area of questioning.

Furthermore, the study methods of interviewing and elucidating questions take substantial time and effort regarding data collection, organization, and analysis. Only 26 participants were interviewed in this study limiting the generalizability of the results. More studies are needed to corroborate findings. Furthermore, studies of larger cross-sectional and longitudinal samples would benefit this research trajectory regarding wisdom and curiosity.

This trajectory should also include how wisdom and curiosity link to health and quality of life variables such as loneliness. For example, Healthy Aging researchers like Dr. Dilip Jeste suggest that, "An inverse relationship exists between loneliness and wisdom" [68]. Perhaps, wisdom and curiosity may or should become pillars of successful aging much like social relationships and networks have $[69,70]$. Such notions fall in line with allowing older adults, as experts in their own rights, to choose the markers of successful aging [70]. Finally, future efforts might further explore the concepts of wise decisions and decision-making in older adulthood.

\section{Conclusions}

Wisdom and curiosity are pursuits of lifelong learners, lifelong learning programs, and lifelong learning researchers $[29,67]$. This study in particular connects big and beautiful questions [6] and questioning as a method to elucidate the dimensionality of wisdom amalgamation and curiosity pursuits within from older adult learners. While subthemes of wisdom and curiosity were unearthed, older adults shared the importance of being open, asking questions, diving wide and deep into topics, finding purpose and meaning, and making wise decisions. This study demonstrates that questions, especially those big and beautiful, can and should be used in future wisdom and curiosity research concerning older adulthood. Future investigators will see why.

\section{Acknowledgments}

This study acknowledges the work of Mikulas Pstross in the data analysis of this study as well as his contributions to theory and methods development. Cindy Warren assisted in the copy-editing of the manuscript prior to submission for review.

\section{Author Contributions}

Craig Talmage contributed to reviewing the literature, developing the study methods, synthesizing the data analysis, and writing the manuscript. 
Richard Knopf contributed to developing the methods, conducting the interviews for data collection, and writing the manuscript.

\section{Funding}

The research was funded by the Osher Lifelong Learning Institute at Arizona State University.

\section{Competing Interests}

The authors have declared that no competing interests exist.

\section{References}

1. Bateson MB. In search of active wisdom. Boomers and Beyond: Reconsidering the role of libraries. Chicago, IL: American Library Association. 2010; 49-56.

2. Maxwell N. From knowledge to wisdom: Assessment and prospects after three decades. Integral Rev. 2013; 9: 76-112.

3. Sakaki M, Yagi A, Murayama K. Curiosity in old age: A possible key to achieving adaptive aging. Neurosci Biobehav Rev. 2018; 88: 106-116.

4. Galli G, Sirota M, Gruber MJ, Ivanof BE, Ganesh J, Materassi M, et al. Learning facts during aging: the benefits of curiosity. Exp Aging Res. 2018; 23: 1-8.

5. Swan GE, Carmelli D. Curiosity and mortality in aging adults: A 5-year follow-up of the Western Collaborative Group Study. Psychol Aging. 1996; 11: 449-453.

6. Berger W. A more beautiful question: The power of inquiry to spark breakthrough ideas. 1st ed. New York, NY: Bloomsbury Publishing; 2014.

7. Le Roux K. The realisation of meaning in old age. Educare. 1999; 28: 121-135.

8. Garnet D, Sinner A, Walker C, Esmat R, Yi S. Learning in the third age: drawing wisdom from reflective stories in community art education. Int J Lifelong Educ. 2018; 37: 283-296.

9. Tell H. Sages at the games: Intellectual displays and dissemination of wisdom in ancient Greece. Classical Antiquity. 2007; 26: 249-75.

10. Van Zyl AE. Plato: the relevance for today's education. Universiteit van Suid-Afrika University of South Africa. 1999; 28: 84-92.

11. Moraitou D, Efklides A. Wise thinking, hopeful thinking, and positive aging: Reciprocal relations of wisdom, hope, memory, and affect in young, middle-aged, and older adults. A Positive Psychology Perspective on Quality of Life. 2012; 189-218.

12. Staudinger UM, Glück J. Psychological wisdom research: Commonalities and differences in a growing field. Ann Rev Psychol. 2011; 62: 215-241.

13. Erikson EH, Erikson JM, Kivnick HQ. Vital involvement in old age. New York, NY: WW Norton \& Company; 1994.

14. Choi NG, Landeros C. Wisdom from life's challenges: Qualitative interviews with low-and moderate-income older adults who were nominated as being wise. J Gerontol Soc Work. 2011; 54: 592-614.

15. Ho HC, Yeung DY, Kwok SY. Development and evaluation of the positive psychology intervention for older adults. J Posit Psychol. 2014; 9: 187-197. 
16. Seligman ME. Flourish: A visionary new understanding of happiness and well-being. New York, NY: Simon and Schuster; 2012.

17. Moraitou D, Efklides $A$. The wise thinking and acting questionnaire: The cognitive facet of wisdom and its relation with memory, affect, and hope. J Happiness Stud. 2012; 13: 849-873.

18. Nordstrom NM, Merz JF. Learning later, living greater: The secret for making the most of your after-50 years. Johannesburg, South Africa: Sentient Publications; 2006.

19. Merriam SB, Caffarella RS, Baumgartner LM. Learning in adulthood: A comprehensive guide. San Francisco, CA: John Wiley \& Sons; 2012.

20. Russell H. Later life: A time to learn. Educat Gerontol. 2008; 34: 206-224.

21. Luppi E. Education in old age: An exploratory study. Int J Lifelong Educ. 2009; 28: 241-276.

22. Bluck $S$, Glück J. Making things better and learning a lesson: Experiencing wisdom across the lifespan. J Pers. 2004; 72: 543-572.

23. Randall WL, Kenyon GM. Time, story, and wisdom: Emerging themes in narrative gerontology. Can J Aging. 2004; 23: 333-346.

24. Alea N, Vick SC, Hyatt AM. The content of older adults' autobiographical memories predicts the beneficial outcomes of reminiscence group participation. J Adult Dev. 2010; 17: 135-145.

25. Farquhar L. Words on wisdom: perspective transformation in a "learning in retirement institute". Applied Psychology. DOI: 10.1111/1464-0597.00047.

26. Farquhar L. Wisdom in a learning in retirement institute. Educ Gerontol. 2010; 36: 641-653.

27. Jarvis P. Wisdom and the Quest for Meaning. Intergenerational Solidarity and Older Adults' Education in Community. 2012; 20-33.

28. Jarvis P. Teaching, learning, and the human quest: Wisdom. New Direc Adult Contin Educ. 2011; 2011: 85-93.

29. Pstross M, Talmage C, Peterson C, Knopf R. In search of transformative moments: Blending community building pursuits into lifelong learning experiences. J Educ Cult Soc. 2017; 7: 62-78.

30. Narushima M. Transformation toward what end? Exploring later life learning in community volunteering. Adult Educ Res Confer. https://newprairiepress.org/aerc/2000/papers/58.

31. Trowbridge RH. Wisdom and lifelong learning in the twenty-first century. London Rev Educ. 2007; 5: 159-172.

32. Lamb FF, Brady EM, Lohman C. Lifelong resiliency learning: A strength-based synergy for gerontological social work. J Gerontol Soc Work. 2009; 52: 713-728.

33. Formosa M. Education and older adults at the University of the Third Age. Educ Gerontol. 2012; 38: 114-126.

34. Wolf MA. Lifespan learners: Educational perspectives. LLIReview. 2006; 1: 1-10.

35. Bencivenga R. The 'digital curious': first steps towards a new typology for mapping adults' relationships with others when using ICT. Eur J Res Educ Learning Adults. 2017; 8: 55-76.

36. Renner B. Curiosity about people: The development of a social curiosity measure in adults. J Pers Assessment. 2006; 87: 305-316.

37. Ramscar $M$, Hendrix $P$, Shaoul C, Milin P, Baayen $H$. The myth of cognitive decline: Non-linear dynamics of lifelong learning. Top Cogn Sci. 2014; 6: 5-42.

38. Moody HR. Structure and agency in late-life learning. Old Age and Agency. Nova Science Publishers: New York. 2004.

39. Strom PS, Strom RD. Thinking in childhood and adolescence. IAP; 2013. 
40. Talmage CA, Lacher RG, Pstross $M$, Knopf RC, Burkhart KA. Captivating lifelong learners in the third age: Lessons learned from a university-based institute. Adult Educ Quart. 2015; 65: 232249.

41. Parvizi J, Tarity TD, Conner K, Smith JB. Institutional review board approval: why it matters. JBJS. 2007; 89: 418-426.

42. Lietz CA, Zayas LE. Evaluating qualitative research for social work practitioners. Adv Soc Work. 2010; 11: 188-202.

43. Miche M, Wahl HW, Diehl M, Oswald F, Kaspar R, Kolb M. Natural occurrence of subjective aging experiences in community-dwelling older adults. J Gerontol B Psychol Sci Soc Sci. 2014; 69: 174-187.

44. Brougham RR, Walsh DA. Early and late retirement exits. Int J Aging Hum Dev. 2009; 69: 267286.

45. Paul R, Elder L. Critical thinking: Teaching students how to study and learn (part I). J Dev Educ. 2002; 26: 36.

46. Lin HR. Searching for meaning: narratives and analysis of US-resident Chinese immigrants with metastatic cancer. Cancer Nurs. 2008; 31: 250-258.

47. Tornstam L. Maturing into gerotranscendence. J Trans Psychol. 2011; 43: 166-180.

48. Talmage CA, Ross A, Searle MS, Knopf RC. The Social and Cognitive Transformation of Older Adult Women: an Analysis of Community Well-Being for a University-Based Lifelong Learning Community. Int J Commun Well-Being. 2018; 1: 11-31.

49. Bangen KJ, Meeks TW, Jeste DV. Defining and assessing wisdom: A review of the literature. Am J Geriatr Psychiatry. 2013; 21: 1254-1266.

50. Narushima M. 'Payback time': Community volunteering among older adults as a transformative mechanism. Ageing Soc. 2005; 25: 567-584.

51. Bradley DB. A reason to rise each morning: The meaning of volunteering in the lives of older adults. Generations. 2000; 23: 45-50.

52. Martinez IL, Frick K, Glass TA, Carlson M, Tanner E, Ricks M, et al. Engaging older adults in high impact volunteering that enhances health: recruitment and retention in the Experience Corps $^{\circledR}$ Baltimore. J Urban Health. 2006; 83: 941-953.

53. Villar F, Celdrán M. Generativity in older age: A challenge for universities of the third age (U3A). Educ Gerontol. 2012; 38: 666-677.

54. Ryff CD. Happiness is everything, or is it? Explorations on the meaning of psychological wellbeing. J Pers Soc Psychol. 1989; 57: 1069-1081.

55. Spreng RN, Lockrow AW, DuPre E, Setton R, Spreng KA, Turner GR. Semanticized autobiographical memory and the default-executive coupling hypothesis of aging. Neuropsychologia. 2018; 110: 37-43.

56. Penhale B, Parker J. Working with vulnerable adults. Abingdon, UK: Routledge; 2007.

57. Cusack SA. Developing a lifelong learning program: Empowering seniors as leaders in lifelong learning. Educ Gerontol. 1995; 21: 305-320.

58. Delahaye BL, Ehrich LC. Complex learning preferences and strategies of older adults. Educ Gerontol. 2008; 34: 649-662.

59. Bowling A. Enhancing later life: how older people perceive active ageing?. Aging Ment Health. 2008; 12: 293-301. 
60. Aupers S, Houtman D. Beyond the spiritual supermarket: The social and public significance of new age spirituality. J Contemporary Religion. 2006; 21: 201-222.

61. Hunter EG, Rowles GD. Leaving a legacy: Toward a typology. J Aging Stud. 2005; 19: 327-347.

62. Fortner, BV, Neimeyer RA. Death anxiety in older adults: A quantitative review. Death Stud. 1999; 23: 387-411.

63. Pstross $M$, Corrigan T, Knopf RC, Sung H, Talmage CA, Conroy C, et al. The benefits of intergenerational learning in higher education: Lessons learned from two age friendly university programs. Innov High Educ. 2017; 42: 157-171.

64. Talmage CA, Hansen RJ, Knopf RC, Thaxton SP. Directions for 21st century lifelong learning institutes: Elucidating questions from osher lifelong learning institute studies. Alberta J Educ Res. 2018; 64: 109-125.

65. Parisi JM, Rebok GW, Carlson MC, Fried LP, Seeman TE, Tan EJ, et al. Can the wisdom of aging be activated and make a difference societally? Educ Gerontol. 2009; 35: 867-879.

66. Baltes PB, Smith J. The fascination of wisdom: Its nature, ontogeny, and function. Perspect Psychol Sci. 2008; 3: 56-64.

67. Tisdell EJ, Swartz AL. Adult Education and the Pursuit of Wisdom: New Directions for Adult and Continuing Education, Number 131. Hoboken, NJ; John Wiley \& Sons; 2011.

68. Scutti, S. Study: Loneliness Peaks At Three Key Ages, But Wisdom May Help. 2018.

69. Pennebaker JW, Stone LD. Words of wisdom: Language use over the life span. J Pers Soc Psychol. 2003; 85: 291-301.

70. Reichstadt J, Sengupta G, Depp CA, Palinkas LA, Jeste DV. Older adults' perspectives on successful aging: Qualitative interviews. Am J Geriatr Psychiatry. 2010; 18: 567-575.

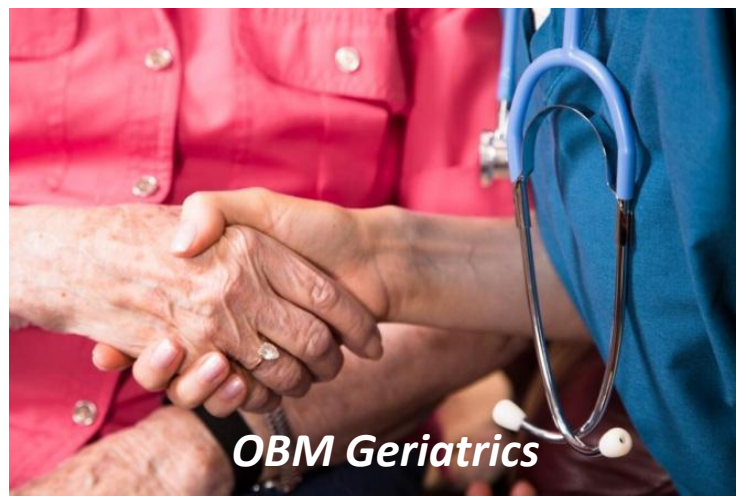

Enjoy OBM Geriatrics by:

1. Submitting a manuscript

2. Joining in volunteer reviewer bank

3. Joining Editorial Board

4. Guest editing a special issue

For more details, please visit: http://www.lidsen.com/journals/geriatrics 